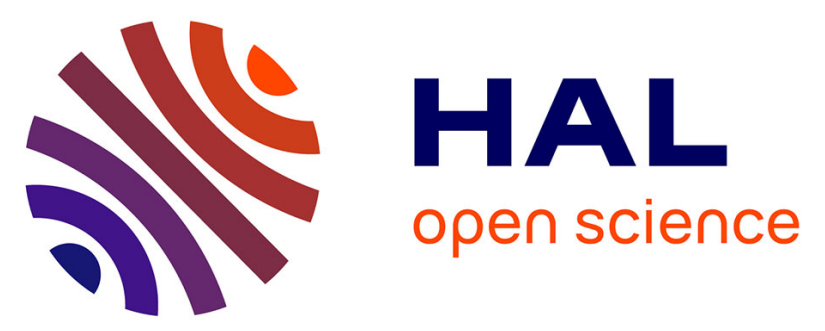

\title{
Administration of brain natriuretic peptide improves cardiac function following operations using the extracorporeal circulation in an animal model
}

Dorothee Hl Bail, Volker Steger, Uli Heinzelmann, Sandra Schiller, Anita I Geim, Benjamin Brüllmann, Gerhard Ziemer

\section{To cite this version:}

Dorothee Hl Bail, Volker Steger, Uli Heinzelmann, Sandra Schiller, Anita I Geim, et al.. Administration of brain natriuretic peptide improves cardiac function following operations using the extracorporeal circulation in an animal model. Clinical Science, 2006, 112 (5), pp.315-324. 10.1042/CS20060136 . hal-00479328

\section{HAL Id: hal-00479328 \\ https://hal.science/hal-00479328}

Submitted on 30 Apr 2010

HAL is a multi-disciplinary open access archive for the deposit and dissemination of scientific research documents, whether they are published or not. The documents may come from teaching and research institutions in France or abroad, or from public or private research centers.
L'archive ouverte pluridisciplinaire HAL, est destinée au dépôt et à la diffusion de documents scientifiques de niveau recherche, publiés ou non, émanant des établissements d'enseignement et de recherche français ou étrangers, des laboratoires publics ou privés. 
Administration of brain natriuretic peptide improves cardiac function following operations using the extracorporeal circulation in an animal model

Dorothee H.L.Bail, Volker Steger, Uli Heinzelmann, Sandra Schiller, Anita I.Geim, Benjamin Brüllmann, Gerhard Ziemer

Department of Thoracic, Cardiac and Vascular Surgery, University of Tuebingen, Germany

Short title: Brain natriuretic peptide administration in cardiac surgery

Corresponding author:

Dorothee H.L. Bail MD

Dept. of Thoracic, Cardiac and Vascular Surgery

University Tuebingen

Hoppe-Seyler Str. 3

D-72076 Tuebingen

Germany

Phone +4970712987675

Fax $\quad+4970714047$

e-mail: dodobail@web.de

Keywords: BNP, cardiac surgery, extracorporeal circulation, cardiac output, catecholamines

Word count:

Abstract: $\quad 250$

Manuscript: $\quad 4235$ 


\section{Abstract}

The critical phase during cardiosurgical procedures is weaning the diseased heart from extracorporeal circulation. Postischemic heart failure sometimes requires the administration of inotropic and/or vasconstrictive agents. The natriuretic peptides influence pre- and afterload through their natriuretic, diuretic and vasodilating actions. To date, there are only few informations concerning the therapeutic effect of brain natriuretic peptide administration during cardiosurgical procedures. The goal of this study was to evaluate the effect of brain natriuretic peptide (BNP) administration following extracorporeal circulation in an animal model.

Surgery was performed on twenty swine using extracorporeal circulation. A 30-minute ischemic episode was simulated. Following declamping, BNP was administered to the BNP group $(\mathrm{n}=10)$ by an IV bolus at $0.3 \mu \mathrm{g} / \mathrm{kg} / \mathrm{min}$ followed by an infusion at a rate of $0.015 \mu \mathrm{g} / \mathrm{kg} / \mathrm{min}$ for 60 minutes. The animals in the control group $(\mathrm{n}=10)$ did not receive BNP, but instead a saline solution. Hemodynamic and clinical chemistry parameters as well as the amount of catecholamines that were required were documented.

All of the animals in the BNP group had a significantly better cardiac output and cardiac index at the end of the experiment. Seven out of 10 animals from the control group needed catecholamines, whereas only one animal from the BNP group did. Creatine phosphokinase levels were significantly lower in the BNP group. Systemic vascular resistance was markedly lower in the BNP group.

Administration of BNP is highly effective in treating post-ischemic heart failure following extracorporeal circulation. Hemodynamics are greatly improved, and there is almost no need for pharmacological support.

\section{Copyright 2006 The Biochemical Society}




\section{Introduction}

The natriuretic, diuretic and vasodilating effects of the natriuretic peptides lead to a decrease in preand afterload, an improvement in myocardial ischemia by vasodilating the coronary arteries, and an increase in stroke volume, which in turn improves left ventricular function [1]. Patients with heart failure or left ventricular dysfunction have elevated plasma concentrations of BNP proportional to the severity of disease.

Various studies have examined the intravenous administration of BNP/Nesiritide [2-4]. All of these studies demonstrated a distinct improvement in hemodynamic parameters. A dose-dependent reduction in pulmonary capillary wedge pressure (PCWP), right atrial pressure (RAP), pulmonary arterial pressure (PAP), mean arterial pressure (MAP), systemic vascular resistance (SVR) and as a result, an increase in stroke volume and cardiac index (CI) were shown. Studies of exogenously administered BNP during the stage of acute decompensated heart failure (ADHF) showed a reduction in ventricular filling pressure, which resulted in improved cardiac output (CO) and CI without increasing heart rate (HR) or significantly decreasing the MAP [5].

Compared with other inotropic substances, administration of BNP has not yet been associated with severe adverse effects, especially ventricular arrhythmia, as is seen with dobutamine or phosphodiesterase inhibitors $[6 ; 7]$.

Weaning the patient from extracorporeal circulation (ECC) and the period immediately thereafter is usually the most unstable phase during cardiac surgery. The heart is in a particularly vulnerable situation, since it must resume perfusion of the entire organism after a period of ischemia. Myocardial insufficiency occurs regularly during this phase. The cardiac surgical trauma, induced ischemic cardiac arrest, disturbance in electrolyte and acid base balance, hemodilution and extracorporeal circulation per se can lead to myocardial edema and insufficiency. The administration of intravenous pharmacological support with various combinations of inotropes, vasoconstrictors and vasodilators are part of a well-established treatment concept for stabilizing and, when necessary, increasing cardiac output.

Two of the most important adverse effects of epinephrine and norepineprine are reduced kidney perfusion and tachyphylaxia. In addition, when ventricle function is already impaired preoperatively, catecholamine susceptibility can be partly diminished due to down-regulation of beta-adrenoreceptors. Phosphodiesterase inhibitors, which are administered for acute low-output syndrome or acute, refractory heart failure, lead to pronounced peripheral vasodilation. An $\alpha-1$ sympathomimeticum like norepinephrine is often needed to counteract these adverse effects. Phosphodiesterase inhibitors also have considerable arrhythmogenic effects and can lead to thrombopenia and hepatotoxicity. Overall, the phosphodiesterase inhibitors have many adverse effects.

Comparing the cardiac situation during and immediately following separation from ECC with the conventional stages of heart failure is very limited. There are only a few studies that have evaluated the influence of ECC on plasma BNP concentrations. These are, in part, conflicting [8;9]. There are only few studies to date on the therapeutic effects of the exogenous administration of BNP during cardiac surgery using ECC.

The goal of this study was to clarify whether the exogenous administration of BNP leads to improvement in hemodynamics during and after cardiac surgical procedures using ECC. Our goal was to determine whether BNP administration results in improvement in left ventricular function during the critical phase of cardiac surgery, which is weaning the heart from ECC. The effectiveness of BNP administration was measured in terms of an increase in CO and CI (of at least 10\%), a reduction in RAP and a significant reduction in the need for intravenous agents for circulatory support.

\section{Copyright 2006 The Biochemical Society}




\section{Materials and Methods}

\section{Animals and the extracorporeal circulation}

All animal procedures were approved by the local representatives for animal welfare at the University of Tuebingen, consistent with the Guide for the Care and Use of Laboratory Animals published by the US National Institutes of Health (NIH Publication No. 85-23, revised 1996). Twenty young swine (27 $\pm 0.9 \mathrm{~kg})$ of both sexes were randomised to two groups. Ten animals received intravenous BNP (BNP group). The ten animals who did not receive BNP comprised the control group.

On the day of surgery the swine were premedicated with ketamine (Katavet $\AA$; Pharmacia, Piscataway, NJ), diazepam, azeperone (Stresnil@; $40 \mathrm{mg} / \mathrm{ml}$; Janssen-Cilag, Neuss, Germany) and atropine applied intramuscularly (dorsal neck muscle). Before induction of anaesthesia, indwelling catheters were placed in two ear veins. Anaesthesia was maintained intravenously with $0.0072 \mathrm{mg} / \mathrm{kg} / \mathrm{min}$ fentanyl, $0.06 \mathrm{mg} / \mathrm{kg} / \mathrm{min}$ flunitrazepam and $0.104 \mathrm{mg} / \mathrm{kg} / \mathrm{min}$ propofol. Before median sternotomy, fluid-filled catheters were inserted into the common carotid artery and the internal jugular vein to monitor arterial and central venous pressures, take arterial and venous blood samples, and to administer fluids.

All swine received $300 \mathrm{IU} / \mathrm{Kg}$ heparin for systemic anticoagulation. In addition, all animals received $250 \mathrm{mg}$ of methylprednisolone (Urbason ${ }^{\circledR}$ solubile forte, Aventis Pharma Deutschland GmbH, frankgurt a.M., Germany) to prevent cross reactions with foreign swine blood which was used to prime the ECC.

ECC was initiated by cannulating the ascending aorta (14 Fr arterial perfusion cannula, Jostra, Hirrlingen, Germany) and the right atrium (32-34 Fr 2-stage venous cannula, Stöckert CAPS, Munich, Germany). After connection to the ECC, a catheter was also inserted in the left atrial appendage for measuring the left atrial pressure (LAP). Cardioplegic arrest was induced by antegrade infusion of a cold $\left(4^{\circ} \mathrm{C}\right)$ blood cardioplegic solution (Buckberg), accomplishing external cooling with instillation of a cold saline solution into the pericardium. The heart was left in cardioplegic cardiac arrest for 30 minutes. The rewarming period to reach a normal body temperature was begun several minutes before the aortic cross clamp (AXCL) was removed. The entire duration of aortic cross clamping was 30 minutes. After the AXCL was removed and defibrillation was performed to convert the heart to a normal rhythm, a reperfusion period (with ECC maintained) of approximately 10 minutes followed, which was equivalent to $1 / 3$ of the AXCL-time. During the subsequent 60 minutes (after weaning the heart from the ECC) pharmacological support was used when necessary (epinephrine, norepinephrine, dopamine) to sustain a minimum MAP of approximately $60 \mathrm{mmHg}$. At the end of the experiment, the animals were euthanized with an overdose of anesthesia and intracardial instillation of potassium (60 mval).

\section{Intravenous administration of BNP}

Various studies [5;10] favor a single BNP bolus application as a loading dose with subsequent continual administration in a lower dose over a defined period of time. We prepared the following protocol on the basis of information in the literature.

Porcine BNP-32 (BNP-32 trifluoroacetate salt; Bachem, Distribution Service GmbH; Weil a. Rhein, Germany) was administered (aqua ad injectabile) intravenously through central venous cannulation immediately

\section{Copyright 2006 The Biochemical Society}


after releasing the aortic clamp. The BNP solution was prepared by dissolving the calculated amount of porcine BNP in $5 \%$ dextrose $(50 \mathrm{ml})$.

BNP group: $(n=10)$

$0.3 \mu \mathrm{g} / \mathrm{kg}$ BNP was administered by an IV bolus directly after reopening the AXCL followed by an infusion at a rate of $0.015 \mu \mathrm{g} / \mathrm{kg} / \mathrm{min}$ for 60 minutes [5].

Control group: $(\mathrm{n}=10)$

No BNP, placebo injection of $50 \mathrm{ml} 0.9 \%$ saline.

\section{Determination of hemodynamic parameters}

$\mathrm{CO}$ was measured following sternotomy, pericardiotomy and preparation of the large vessels using a Transonic ${ }^{\circledR}$ perivascular ultrasonic volume flow sensor placed directly on the ascending aorta just above the aortic root (Transsonic Systems, Ithaca NY, USA). In addition, CO was measured at regular intervals until the end of the experiment. The RAP, MAP and the LAP were measured continually during the entire experiment with a catheter. The $\mathrm{CI}$ was calculated from $\mathrm{CO}$ and body surface area (BSA) (CI = CO/BSA; Table 1). The systemic vascular resistance (SVR) was calculated from the values of MAP, RAP and CO (Table 1).

\section{Determination of metabolic and biochemical parameters}

While the hemodynamic parameters were being recorded, the metabolic status (including lactate) was evaluated by analysing atrial blood gas samples. Levels of creatine phosphokinase (CPK), a sensitive and specific marker for myocardial damage, were measured once before ECC, then in regular intervals using the method of ADVIA chemistry systems ${ }^{\circledR}$ from Bayer (Bayer AG, Leverkusen, Germany) together with human probes in the laboratory of the University of Tuebingen .

\section{Determination of Plasma-BNP concentrations}

Blood samples for P-BNP were collected in chilled plastic tubes containing EDTA, place immediately on ice, centrifugated within $20 \mathrm{~min}$. at $4^{0} \mathrm{C}$ and stored at $-70^{\circ} \mathrm{C}$ until assayed. Plasma levels of P-BNP were determined after extraction with a conventional available RIA-Kit for porcine BNP (Host: Rabbit, Range:1-128 pg/tube; Standard Peptide: $128 \mu$ g, Peninsula Laboratories, Inc. Division of Bachem, San Carlost, CA, USA). The minimal detectable amount of the assay was $1 \mathrm{pg} /$ tube. The intraassay and interassay coefficient of variation was $8,5 \%$ and $10,5 \%$. 


\section{Measurement times}

The measurements of hemodynamic and clinical chemistry parameters took place at the following time intervals:

preoperatively following induction of anesthesia and after sternotomy:

preop

after beginning ECC:

ECC start

after declamping the aorta: (iv BNP-Bolus)

AXCL open

immediately after ending ECC:

ECC end

15 minute intervals up to 60 minutes after ending ECC:

$15 \mathrm{~min}-60 \mathrm{~min}$

\section{Further parameters}

The amount of intravenous vasoactive agents required (dopamine, epinephrine, norepinephrine) to maintain an adequate perfusion pressure during ECC and the amount of fluids administered was documented. Colloid and crystalloid fluids were given intravenously when MAP levels fell below $60 \mathrm{mmHg}$ in combination with a low cardiac filling pressure. In the case of increased left ventricular filling pressure or high SVR, inotropic (adrenalin, dopamine) and/or vasoconstrictive agents (noradrenalin) were administered.

\section{Statistics}

All analyses were performed with SPSS 12.0 software. All results are stated as mean values \pm SEM. The number of test animals was calculated in collaboration with the Institute for Med. Biometrics at the University of Tuebingen (Director Prof. Dr. K. Dietz; Dr. R. Vonthein). Oneway-Anova-Analysis (with levene-Test for inhomogenous variances) was used to calculate the significance of BNP-induced hemodynamic changes between the two groups for normally distributed data (Shapiro-Wilk-Test). Non-parametric tests (Mann-Whitney) were used for non-normally distributed data. The Fisher's Exact test procedure was used to calculate an exact probablity value for the relationship between dichotomous variables. P-values $<0.05$ indicated statistical significance.

\section{Results}

\section{Cardiac output, cardiac index and cathecholamines}

Prior to ECC, neither group showed a difference in CO or CI. After ending ECC, there was still no difference between the two groups. Fifteen minutes after ending ECC until the end of the experiment (60 minutes), the animals in the BNP group had a significantly higher CO (control group: $2.3 \pm 0.4$ vs. BNP group: $3.3 \pm$ $0.2 \mathrm{l} / \mathrm{min} ; \mathrm{p}<0.039$ ) and a significantly higher CI (control group: $2.47 \pm 0.4$ vs. BNP group: $3.96 \pm 0.21 / \mathrm{min} / \mathrm{m}^{2}$; $\mathrm{p}<0.0027$ ) than the animals in the control group (Table 1, Figure 1 and Figure 2).

On average, the animals in the BNP group had a $41 \%$ (960 ml/min) higher CO than the animals in the control group after 60 minutes of independent cardiac activity. The control group's CO was slightly lower at

\section{Copyright 2006 The Biochemical Society}


approximately 9\%. Delta CO (initial values compared with values at the end of the experiment) was higher than the initial values in the BNP group, whereas $\triangle \mathrm{CO}$ in the control group was lower ( $\triangle \mathrm{CO}$ in the control group: $0.22 \pm 0.3 \mathrm{l} / \mathrm{min} ; \Delta \mathrm{CO}$ in the BNP group: $0.62 \pm 0.2 ; \mathrm{p}<0.035$; Table 2 ).

The CI in the BNP group was $60 \%$ higher than in the control group at the end of the experiment. The CI in the BNP group showed an increase of $23 \%$ compared with the initial values (Delta $\mathrm{CI}) . \Delta \mathrm{CI}$ in the BNP group was significantly higher than in the control group $(\Delta \mathrm{CI}$ in the control group: $-0.27 \pm 0.31$ vs. $0.74 \pm 0.24$ 1/min/m²; BNP group: $\mathrm{p}<0.019$; Table 2 ).

From the beginning of the experiment, during ECC and after reopening the AXCL, a number of animals in both groups needed intravenous catecholamines (dopamine, norepinephrine, epinephrine) in order to maintain an adequate perfusion pressure during ECC. Seven out of 10 (70\%) animals in the control group needed pharmacological support until the end of the experiment and during the entire phase of independent cardiac activity. Only $3(30 \%)$ animals from the BNP group needed catecholamines by the end of ECC. Only one animal in the BNP group needed pharmacological support in a lower dosage at the end of the experiment, which was after 60 minutes of independent cardiac activity. The animals in the BNP group needed significantly less catecholamines than those in the control group during the entire phase of independent cardiac action after ending ECC (60 minutes after ending ECC: p<0.001; Figure 3, Table 3).

\section{Mean arterial pressure (MAP)}

The mean arterial pressure (MAP) did not differ significantly throughout the entire experiment in either group (Table 1). However, $70 \%$ of the animals in the control group needed catecholamines after ending ECC to sustain a minimum MAP of $60 \mathrm{mmHg}$. $\triangle \mathrm{MAP}$ (preop-60 minutes) was not significantly different between groups (Table $\underline{2}$ ).

\section{Systemic vascular resistance (SVR)}

SVR did not vary between groups at the beginning of the experiment. However, clear differences were already seen 15 minutes after ending ECC. The animals in the BNP group had markedly lower SVR values until the end of the experiment, although it was not significant (Table 1; Figure 4). $\Delta \mathrm{SVR}$ (preop-60 minutes) was significantly lower ( $<<0.04$; Table 2). The median SVR in the control group was not significantly higher at the end of the experiment than it was at the beginning.

\section{Creatine phosphokinase (CPK)}

There was no difference in CPK levels between the two groups at the beginning of the experiment until the start of ECC. During ECC, CPK levels increased in both groups and remained elevated in the control group. The animals in the BNP group had significantly lower CPK values after opening the AXCL until the end of the experiment (Table $\underline{3}$, Figure 5). $\Delta \mathrm{CK}$ levels (preop-60 minutes) were significantly lower in the BNP group $(\mathrm{p}<0.0049$; Table 2).

\section{Copyright 2006 The Biochemical Society}




\section{Right atrial pressure (RAP)}

The RAP did not vary between the groups at the beginning of the experiment. Fifteen minutes after ending ECC, the RAP in the BNP group was significantly lower (control group: $10.5 \pm 0.8$ vs. BNP group: $8.0 \pm 0.8$ $\mathrm{mmHg}$; $\mathrm{p}<0.04)$. However, there was no other significant difference in RAP between the groups at any time throughout the experiment (Table 1 and 2 ).

\section{Plasma-BNP concentrations}

Preoperatively the BNP concentration was equally low in the control group and in BNP-treated animals (Control group: $9.0 \pm 1.2$; BNP group: $9.8 \pm 1.1 \mathrm{pg} / \mathrm{ml}$; Table 4 ). After connecting to the ECC, the plasma BNPconcentration increased significantly in both groups. In the control group the BNP plasma concentration declined after AXCL was removed. However, at further time points the BNP-concentrations were still higher than preoperatively. In BNP-treated animals BNP was administrated after removement of the AXCL. BNP was given as a single bolus $(0,3 \mu \mathrm{g} / \mathrm{kg})$ followed by continous infusion for one hour $(0,015 \mu \mathrm{g} / \mathrm{kg} / \mathrm{min})$. The highest BNP concentration in plasma was measured immediately after the bolus application. Further on the measured BNP values in plasma of the treated animals were constantly high until the end of the experiment (Table 4 ).

\section{Other parameters (Lactate, LAP, HR)}

There was no difference in mean lactate values between groups at the beginning of the experiment. During ECC, lactate was increased in both groups. Sixty minutes after ECC, lactate values decreased slightly in the BNP group (Table 3). The LAP was low (approximately $5 \mathrm{mmHg}$ ) before ECC in both groups and increased up to $10 \mathrm{mmHg}$ after ending ECC until the end of the experiment (Table 1 and Table 2 ). The mean heart rate at the end of the experiment was slightly lower in the BNP group but was not statistically significant (Table 1 and 2).

\section{Fluid administration and urine output}

The total fluid intake in the BNP group was approximately twice that of the control group (control group: $518 \pm 268 \mathrm{ml}$ vs. BNP group: $1580 \pm 149 \mathrm{ml}$; $<<0.003)$. The total urine output was markedly higher in the BNP group than in the control group (control group: $235 \pm 81$ vs. BNP group: $407+151 \mathrm{ml}$; $<<0.021$ ).

\section{Discussion}

This study shows the impressive hemodynamic effects of intravenously administered BNP during surgical procedures using extracorporeal circulation. The results demonstrate an outstanding improvement in cardiac output and cardiac index along with a decrease in systemic vascular resistance, almost without the need for inotropic support.

\section{Copyright 2006 The Biochemical Society}


The present results are consistent with other studies of patients who received BNP for either chronic or acute, decompensated heart failure. There are, however, only very limited studies to date evaluating the effects of BNP after operations using ECC [11;12]. The induced myocardial ischemia and "postischemic heart failure" caused by multiple factors, can be only partially compared with other studies. Hayashida et al. [13] studied patients undergoing cardiac surgery who received ANP (atrial natriuretic peptide) perioperatively. Nine patients with mitral valve disease received ANP over 6 hours at a rate of $0.05 \mu \mathrm{g} / \mathrm{kg} / \mathrm{min}$ after beginning ECC. The hemodynamic effect was seen in the form of a decrease in pre- and afterload, a decrease in PCWP, RAP, SVR and a significant increase in CI. At the same time, there were no adverse effects, i.e., hypotension, arrhythmias or allergic reactions to exogenous ANP.

The hemodynamic effects of BNP in the present study coincide with studies on BNP for decompensated heart failure [14-16]. BNP led to a 28\% improvement in CI [17], and in other studies, to an increase of 400 $\mathrm{ml} / \mathrm{m}^{2}[5 ; 14]$ in patients with severe heart failure. In our study, BNP resulted in a significant improvement in CI $\left(60 \%\right.$, or $\left.1,490 \mathrm{ml} / \mathrm{m}^{2}\right)$ and $\mathrm{CO}(41 \%$, or $960 \mathrm{ml} / \mathrm{min})$ compared with the control group.

The administration of BNP led to a rapid vasodilative effect, which resulted in a reduction in pre-and afterload and a decrease in SVR [18]. At the same time, BNP led to an increase in stroke volume and cardiac output. We found a reduction in SVR in the BNP group, which coincides with findings from several other studies $[5 ; 19]$.

In the control group, increased cardial filling pressure and decreased $\mathrm{CO}$ and $\mathrm{CI}$ resulted in the need for catecholamines and a reduction in fluid administration. In the BNP group, the cardiac filling pressure was low. The urine output in the BNP group was significantly higher, which resulted in a higher volume of fluid administration. The greater need for fluids in the BNP group can be explained by the low filling pressure and by the fact that the glomerular filtration rate (GFR) was higher in these animals who did not have pre-existing cardiac disease. Jensen et al. found a higher GFR for in patients with congestive heart failure after treatment with BNP. The sympatoinhibitive effect of BNP reduces renal vascoconstriction, and this reduction, combined with an overall improvement in cardiac output, results in enhanced renal perfusion [20]. In the kidney blood flow and filtration is increased with concomitant natriuresis and diuresis after treatment with BNP [21].

The administration of BNP did not lead to a relevant decrease in MAP (caused by vasodilation of arteries and veins), which is consistent with recent studies [14;19].

The animals in the control group required various catecholamines, sometimes in combination (i.e., epinephrine, norepinephrine and dopamine) to treat myocardial contractile dysfunction caused by post-ischemic heart failure. In contrast, the animals in the BNP group needed almost no inotropic support. Only one animal required noradrenaline at the end of the experiment, and this in a concentration approximately seven times lower than the animals in the control group. Hayashida et al. [14] found that patients in both groups (placebo and ANP) needed approximately the same amount of catecholamines postoperatively. In this study, both groups of patients had severe cardiac disease. In contrast, neither group in our study had cardiac disease. This could account for the differing in results between these studies.

BNP is produced primarily in the left ventricle, and compensatory secretion of BNP is greater than ANP in congestive heart failure. Although the effects of ANP are very similar to BNP, ANP has a lesser effect in patients with congestive heart failure [22], and has a shorter elimination time (1-3 min). BNP is used world-wide as recombinant human BNP/Nesiritide since FDA approval in 2001.

\section{Copyright 2006 The Biochemical Society}


$\mathrm{BNP} /$ nesiritide has coronary vasodilative effects on both the coronary artery conductance and resistance. When administered, the coronary artery blood flow is increased, coronary resistance is decreased, and myocardial oxygen uptake is decreased [23]. BNP leads to direct vasodilation of coronary vessels [24]. It also improves reperfusion of the induced myocardial ischemia after ECC. Creatine phosphokinase, an indicator of ischemic myocardial damage, was significantly lower in the BNP group than in the control group, which could be indicative of a positive influence of exogenous BNP on myocardial function, particularly after ischemia [23;25] A further indication of hemodynamic improvement in the BNP group is the lower lactate values after ending ECC which show that the administration of BNP leads to a significant improvement in postischemic heart failure after ECC. Further studies are needed to evaluate the effects of BNP in patients with pre-existing heart failure/impaired cardiac function.

BNP lowers pre- and afterload without reflex tachycardia [26]. It also reduces the release of endogenous catecholamines by the autonomic nervous system [16]. We did not observe reflex tachycardia following the administration of BNP. Reflex tachycardia can cause an increase in myocardial oxygen consumption, as well as an increase in venous pooling and a decrease in vascular tone. None of the animals had a significant change in heart rate while receiving BNP. The heart rate was even slightly lower in the BNP group.

Almost all studies report a significant decrease in RAP after exogenous BNP administration [5]. We, however, could not confirm this. Only at one measurement point (15 minutes after ending ECC) was RAP significant lower in the BNP treated group which was in our view due to bolus administration of the peptide. After declamping the aorta the animals in the BNP group received a bolus dosage 20 times higher than the subsequent infusion rate. The time span from the bolus until 15 minutes after termination of ECC was 25 minutes. The onset of action of BNP following intravenous bolus administration is usually observed within 15-20 Minutes.

BNP's effect is similar to nitroglycerin, although the reduction of PCWP is greater [27-29]. The LAP values, which correspond to the PCWP, remained unchanged following BNP administration. However, the animals in both groups did not have heart disease and, therefore, did not have elevated PCWP/LAP values preoperatively.

The observed increase in cardiac output and cardiac index is entirely due to afterload reduction secondary to vasodilation [20]. The positive hemodynamic effects of BNP do not cause an increase in oxygen consumption since it is not dependent on the andrenergic receptor system [14]. No severe adverse effects have been reported yet, in contrast to other drugs used to treat heart failure or low-output syndrome. The improvement in hemodynamics is not caused by a secondary increase in intracellular cyclic AMP and calcium, as is the case with positive inotropic substances (e.g. dobutamine). Therefore, arrhythmias were not seen during BNP administration. A major advantage of BNP over phosphodiesterase inhibitors is the shorter half-life, which makes it easier to control. The other adverse effects associated with phosphodiesterase inhibitors like arrhythmia, hepatotoxicity and peripheral vasodilation do not occur with BNP. Peripheral vasodilation caused by phosphodiesterase inhibitors must often be counteracted with norepinephrine, which causes decreased kidney and intestinal perfusion.

Sackner-Bernstein et al. (Circulation 2005) [30] showed an impaired renal function after nesiritide treatment. However, this study should be considered carefully in respect to our data because it is meta-analysis of studies involving patients with acute decompensated heart failure (ADHF). The disease pattern of ADHF may involve many factors that could result in elevated serum creatinine levels, rather than it may be an effect by BNP therapy itself. In addition the surgical procedere involving ECC may affect renal function per se. Furthermore the analysis was based on a nonavailabilty of primary study data. We believe that in our study, 60 minutes is too

\section{Copyright 2006 The Biochemical Society}


short to determine any change in renal function. In fact, in our study like in others diuresis was clearly improved in BNP-treated animals.

One limitation of this study was that the animals did not have heart disease or heart failure preoperatively, represented by the low BNP concentration preoperatively. Nevertheless, in both groups BNP concentration rised significantly after ECC was connected. The results of the control group clearly show that procedures using ECC which cause ischemia result in a significant increase in Plasma-BNP and in a decline in myocardial function and the need for catecholamines postoperatively. In BNP-treated swines on the other side, BNP levels arised after bolus injection of BNP and stayed constantly high thereafter until the end of the experiment. Following bolus administration and inititation of a continuous infusion, $60 \%$ of the steady-state hemodynamics response is observed within 15 minutes and $95 \%$ with 1 hour [31].

BNP demonstrates excellent effects, especially in the case of severely impaired myocardial function. Further studies are needed involving hearts with pre-existing heart disease. These patients are often difficult to wean from ECC, and need high doses of pharmacological support. Postischemic heart failure is one of the main reasons for a greater demand for catecholamines and for a decline in myocardial contractile function following cardiac operations. Therefore, a further limitation of this study is the relatively short duration of ischemia, namely 30 minutes. Even so, the animals in the control group had an increase in Plasma-BNP_and a decline in contractile function and even though they received inotropic support (epinephrine).

\section{Conclusions}

The present study shows BNP to be a highly potent, readily available agent that offers significant advantages, especially in cardiac surgery. When planning this experiment, we expected an increase in cardiac output and cardiac index of at least $10 \%$ and a considerable decrease in vasoactive agents for circulatory support. These expectations were greatly exceeded.

\section{Copyright 2006 The Biochemical Society}




\section{Reference List}

1. Baxter,G.F. (2004) The natriuretic peptides. Basic Res.Cardiol. 99, 71-75.

2. Hobbs,R.E., Miller,L.W., Bott,S.C., James,K.B., Rincon,G. and Grossbard,E.B. (1996) Hemodynamic effects of a single intravenous injection of synthetic human brain natriuretic peptide in patients with heart failure secondary to ischemic or idiopathic dilated cardiomyopathy. Am J Cardiol 78, 896-901.

3. Marcus,L.S., Hart,D., Packer,M. et al. (1996) Hemodynamic and renal excretory effects of human brain natriuretic peptide infusion in patients with congestive heart failure. Circulation 94, 3184-3189.

4. Yoshimura,M., Yasue,H., Morita,E. et al. (1991) Hemodynamic, renal, and hormonal responses to brain natriuretic peptide infusion in patients with congestive heart failure. Circulation 84, 1581-1588.

5. Colucci,W.S., Elkayam,U., Horton,D.P. et al. (2000) Intravenous Nesiritide, a natriuretic peptide, in the treatment of decompensated congestive heart failure. N Engl J Med 343, 246-253.

6. Biddle,T.L., Benotti,J.R., Creager,M.A. et al. (1987) Comparison of intravenous milrinone and dobutamine for congestive heart failure secondary to either ischemic or dilated cardiomyopathy. Am.J.Cardiol. 59, $1345-1350$.

7. Smull,D.L. and Jorde,U.P. (2005) Concomitant use of nesiritide and milrinone in decompensated congestive heart failure. Am.J.Health Syst.Pharm. 62, 291-295.

8. Ationu,A., Burch,M., Elliott,M. and Carter,N. (1993) Brain natriuretic peptide and fluid volume homeostasis--studies during cardiopulmonary bypass surgery. Clin.Auton.Res. 3, 275-280.

9. Morimoto,K., Mori,T., Ishiguro,S., Matsuda,N., Hara,Y. and Kuroda,H. (1998) Perioperative changes in plasma brain natriuretic peptide concentrations in patients undergoing cardiac surgery. Surg. Today $\mathbf{2 8 ,} 23-$ 29.

10. Mills,R.M., LeJemtel,T.H., Horton,D.P. et al. (1999) Sustained hemodynamic effects of an infusion of nesiritide (human b-type natriuretic peptide) in heart failure: a randomized, double-blind, placebocontrolled clinical trial. Natrecor Study Group. J Am Coll Cardiol 34, 155-162.

\section{Copyright 2006 The Biochemical Society}


11. Moazami,N., Damiano,R.J., Bailey,M.S. et al. (2003) Nesiritide (BNP) in the management of postoperative cardiac patients. Ann.Thorac.Surg 75, 1974-1976.

12. Samuels,L.E., Holmes,E.C. and Lee,L. (2004) Nesiritide as an adjunctive therapy in adult patients with heart failure undergoing high-risk cardiac surgery. J.Thorac.Cardiovasc.Surg. 128, 627-629.

13. Hayashida,N., Chihara S., Kashikie,H. et al. (2000) Effects of intraoperative administration of atrial natriuretic peptide. Ann.Thorac.Surg. 70, 1319-1326.

14. Maisel,A.S. (2003) Nesiritide: a new therapy for the treatment of heart failure. Cardiovasc Toxicol. 3, 37 42.

15. Hobbs,R.E. (2003) Using BNP to diagnose, manage, and treat heart failure. Cleve.Clin.J.Med. 70, 333336.

16. Suttner,S.W. and Boldt,J. (2004) Natriuretic peptide system: physiology and clinical utility. Curr.Opin.Crit Care 10, 336-341.

17. Abraham,W.T., Lowes,B.D., Ferguson,D.A. et al. (1998) Sytemic hemodynamic, neurohormonal, and renal effects of a steady-state infusion of human brain natriuretic peptide in patients with hemodynamically decompensated heart failure. J Cardiac Failure 4, 37-44.

18. Corti,R., Burnett,J.C.J., Rouleau,J., Ruschitzka,F. and Luscher,T.F. (2001) Vasopeptidase inhibitors: a new therapeutic concept in cardiovascular disease? Circulation 104, 1856-1862.

19. Brunner-La Rocca,H.P., Kaye,D.M., Woods,R.L., Hastings,J. and Esler,M.D. (2001) Effects of intravenous brain natriuretic peptide on regional sympathetic activity in patients with chronic heart failure as compared with healthy control subjects. J Am Coll Cardiol 37, 1221-1227.

20. Burger,A.J. (2005) A review of the renal and neurohormonal effects of B-type natriuretic Peptide. Congest.Heart Fail. 11, 30-38.

21. Houben,A.J., van der Zander,K. and de Leeuw,P.W. (2005) Vascular and renal actions of brain natriuretic peptide in man: physiology and pharmacology. Fundam.Clin.Pharmacol. 19, 411-419.

\section{Copyright 2006 The Biochemical Society}


22. Jensen,K.T., Eiskjaer,H., Carstens,J. and Pedersen,E.B. (1999) Renal effects of brain natriuretic peptide in patients with congestive heart failure. Clin.Sci.(Lond) 96, 5-15.

23. Zellner,C., Protter,A.A., Ko,E. et al. (1999) Coronary vasodilator effects of BNP: mechanisms of action in coronary conductance and resistance arteries. Am J Physiol Heart and Circ Physiol 45, H1049-H1057.

24. Matsumoto,T., Wada,A., Tsutamoto,T. et al. (1999) Vasorelaxing effects of atrial and brain natriuretic peptides on coronary circulation in heart failure. Am J Physiol 276, H1935-H1942.

25. Michaels,A.D., Klein,A., Madden,J.A. and Chatterjee,K. (2003) Effects of intravenous nesiritide on human coronary vasomotor regulation and myocardial oxygen uptake. Circulation 107, 2697-2701.

26. van der Zander,K., Houben,A.J., Hofstra,L., Kroon,A.A. and de Leeuw,P.W. (2003) Hemodynamic and renal effects of low-dose brain natriuretic peptide infusion in humans: a randomized, placebo-controlled crossover study. Am.J.Physiol Heart Circ.Physiol 285, H1206-H1212.

27. Elkayam,U., Akhter,M.W., Singh,H., Khan,S. and Usman,A. (2004) Comparison of effects on left ventricular filling pressure of intravenous nesiritide and high-dose nitroglycerin in patients with decompensated heart failure. Am.J.Cardiol. 93, 237-240.

28. Peacock,W.F., Emerman,C.L. and Young,J. (2004) Nesiritide in congestive heart failure associated with acute coronary syndromes: a pilot study of safety and efficacy. J.Card Fail. 10, 120-125.

29. de Denus,S., Pharand,Ch. and Williamson,D.R. (2004) Brain natriuretic peptide in the management of heart failure. The versatile Neurohormone. Chest 125, 652-668.

30. Sackner-Bernstein,J.D., Skopicki,H.A. and Aaronson,K.D. (2005) Risk of worsening renal function with nesiritide in patients with acutely decompensated heart failure. Circulation 111, 1487-1491.

31. Kayser,S.R. (2002) The use of nesiritide in the management of acute decompensated heart failure. Prog.Cardiovasc.Nurs. 17, 89-95.

\section{Copyright 2006 The Biochemical Society}


Table 1: Hemodynamic parameters before and after BNP administration: IV BNP administration started after reopening aortic cross clamping with a bolus loading dose and continuous infusion until 60 minutes after ECC end (= end of trial)

\begin{tabular}{|l|l|c|c|c|c|c|c|c|}
\hline Time & Group & $\begin{array}{c}\text { MAP } \\
{[\mathrm{mmHg}]}\end{array}$ & $\begin{array}{c}\text { CO } \\
{[1 / \mathrm{min}]}\end{array}$ & $\begin{array}{c}\text { CI } \\
{\left[1 / \mathrm{min} / \mathrm{m}^{2}\right]}\end{array}$ & $\begin{array}{c}\text { RAP } \\
{[\mathrm{mmHg}]}\end{array}$ & $\begin{array}{c}\text { LAP } \\
{[\mathrm{mmHg}]}\end{array}$ & $\begin{array}{c}\text { HR } \\
{[\mathrm{b} / \mathrm{min}]}\end{array}$ & $\begin{array}{c}\text { SVR } \\
{\left[\mathrm{dyn}^{*} \mathrm{sec}^{*} \mathrm{~cm}^{-5}\right]}\end{array}$ \\
\hline Preop & $\mathrm{BNP}$ & $70.4 \pm 5.3$ & $2.66 \pm 0.15$ & $3.21 \pm 0.5$ & $8.5 \pm 1.0$ & $5.3 \pm 0.8$ & $88.1 \pm 4.1$ & $1757.5 \pm 142$ \\
& Control & $58.5 \pm 5.4$ & $2.55 \pm 0.28$ & $2.74 \pm 0.2$ & $6.8 \pm 0.9$ & $4.9 \pm 1.0$ & $88.5 \pm 3.1$ & $1683.7 \pm 131$ \\
& & $\mathrm{NS}$ & $\mathrm{NS}$ & $\mathrm{NS}$ & $\mathrm{NS}$ & $\mathrm{NS}$ & $\mathrm{NS}$ & $\mathrm{NS}$ \\
\hline ECC End & $\mathrm{BNP}$ & $59 \pm 3.4$ & $2.67 \pm 0.4$ & $3.23 \pm 0.42$ & $10.2 \pm 0.7$ & $10.1 \pm 0.7$ & $121.7 \pm 8.8$ & $1744.9 \pm 195$ \\
& Control & $58.3 \pm 4.2$ & $2.6 \pm 0.3$ & $2.81 \pm 0.15$ & $8.0 \pm 0.8$ & $9.4 \pm 0.7$ & $113.5 \pm 12.1$ & $1636.1 \pm 189$ \\
& & $\mathrm{NS}$ & $\mathrm{NS}$ & $\mathrm{NS}$ & $\mathrm{NS}$ & $\mathrm{NS}$ & $\mathrm{NS}$ & $\mathrm{NS}$ \\
\hline $\begin{array}{l}\mathbf{6 0} \text { min } \\
\text { after ECC }\end{array}$ & $\mathrm{BNP}$ & $65.9 \pm 3.6$ & $3.3 \pm 0.2$ & $3.96 \pm 0.2$ & $9.8 \pm 0.6$ & $9.9 \pm 0.7$ & $97.5 \pm 7.3$ & $1404.6 \pm 93$ \\
& Control & $58.5 \pm 5.4$ & $2.3 \pm 0.4$ & $2.47 \pm 0.4$ & $9.2 \pm 0.9$ & $10.2 \pm 1.7$ & $115.3 \pm 13$ & $1946.9 \pm 277$ \\
& & $\mathrm{NS}$ & $\mathbf{P}<\mathbf{0 . 0 3 9}$ & $\mathbf{P}<\mathbf{0 . 0 0 2 7}$ & $\mathrm{NS}$ & $\mathrm{NS}$ & $\mathrm{NS}$ & $\mathrm{NS}$ \\
\hline
\end{tabular}


Table 2: Differences ( $\triangle$ Delta) of hemodynamic parameters and creatine phosophokinase (CPK) at the end of the experiment compared to the beginning of the experiment. IV BNP administration started after reopening aortic cross clamping with a bolus loading dose and continuous infusion until 60 minutes after $\mathrm{ECC}$ end $=$ end of trial)

\begin{tabular}{|l|l|c|c|c|c|c|c|c|c|}
\hline$\Delta$ Delta & Group & $\begin{array}{c}\Delta \mathbf{C O} \\
{[1 / \mathrm{min}]}\end{array}$ & $\begin{array}{c}\Delta \mathbf{C I} \\
{[1 / \mathrm{min}]}\end{array}$ & $\begin{array}{c}\Delta \mathbf{M A P} \\
{[\mathrm{mmHg}]}\end{array}$ & $\begin{array}{c}\Delta \text { SVR } \\
{\left[\mathrm{dyn}^{*} \mathrm{sec}^{*} \mathrm{~cm}^{-5}\right]}\end{array}$ & $\begin{array}{c}\Delta \mathbf{R A P} \\
{[\mathrm{mmHg}]}\end{array}$ & $\begin{array}{c}\Delta \mathbf{L A P} \\
{[\mathrm{mmHg}]}\end{array}$ & $\begin{array}{c}\Delta \mathbf{H R} \\
{[\mathrm{b} / \mathrm{min}]}\end{array}$ & $\begin{array}{c}\Delta \mathbf{C P K} \\
{[\mathrm{U} / \mathrm{L}]}\end{array}$ \\
\hline Preop- 60'minutes & BNP & $0.62 \pm 0.2$ & $0.74 \pm 0.2$ & $-4.5 \pm 6.6$ & $-352 \pm 245$ & $1.4 \pm 1.0$ & $4.6 \pm 0.9$ & $9 \pm 9$ & $223 \pm 100$ \\
& Control & $-0.22 \pm 0.3$ & $-0.27 \pm 0.3$ & $0 \pm 5.3$ & $263 \pm 133$ & $2.4 \pm 1.2$ & $5.3 \pm 1.8$ & $27 \pm 12$ & $1254 \pm 221$ \\
& & $\mathbf{P}<\mathbf{0 . 0 3 5}$ & $\mathbf{P}<\mathbf{0 . 0 1 9}$ & $\mathbf{N S}$ & $\mathbf{P}<\mathbf{0 . 0 4}$ & $\mathbf{N S}$ & $\mathbf{N S}$ & $\mathbf{N S}$ & $\mathbf{P}<\mathbf{0 . 0 0 4 9}$ \\
\hline
\end{tabular}


Table 3: Creatine phosphokinase (CPK), lactate values and frequency of catecholamines before and after BNP administration: IV BNP administration started after reopening aortic cross clamping with a bolus loading dose and continuous infusion until 60 minutes after ECC end (= end of trial)

\begin{tabular}{|c|c|c|c|c|}
\hline time & Group & $\begin{array}{l}\text { CPK } \\
{[\mathrm{U} / \mathrm{L}]}\end{array}$ & $\begin{array}{c}\text { Lactate } \\
{[\mathrm{mmol} / \mathrm{L}]}\end{array}$ & $\begin{array}{c}\text { Catecholamines } \\
(\mathrm{n})\end{array}$ \\
\hline Preop & $\begin{array}{l}\text { BNP } \\
\text { Control }\end{array}$ & $\begin{array}{c}1015 \pm 455 \\
1191 \pm 924 \\
\text { NS }\end{array}$ & $\begin{array}{c}2.29 \pm 1.6 \\
2.92 \pm 1.8 \\
\mathrm{NS}\end{array}$ & $\begin{array}{c}0 \\
0 \\
0 \\
\text { NS }\end{array}$ \\
\hline ECC End & $\begin{array}{l}\text { BNP } \\
\text { Control }\end{array}$ & $\begin{array}{c}1407 \pm 306 \\
2354 \pm 1034 \\
\mathbf{P}<\mathbf{0 . 0 1 8}\end{array}$ & $\begin{array}{c}5.71 \pm 2.8 \\
5.47 \pm 2.8 \\
\text { NS }\end{array}$ & $\begin{array}{c}3 \\
6 \\
6 \\
\text { NS }\end{array}$ \\
\hline $\begin{array}{l}60 \mathrm{~min} \\
\text { after ECC }\end{array}$ & $\begin{array}{l}\text { BNP } \\
\text { Control }\end{array}$ & $\begin{array}{c}1238 \pm 287 \\
2445 \pm 1361 \\
\mathbf{P}<\mathbf{0 . 0 1 3}\end{array}$ & $\begin{array}{c}5.27 \pm 2.4 \\
6.47 \pm 2.5 \\
\text { NS }\end{array}$ & 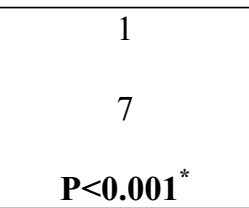 \\
\hline
\end{tabular}

* Fisher's Exact Test 
Table 4: Changes in Plasma-BNP concentrations: IV BNP administration started after reopening aortic cross clamping with a bolus loading dose and continuous infusion until 60 minutes after ECC end $(=$ end of trial $)$

\begin{tabular}{|l|l|l|l|l|l|l|l|l|l|}
\hline $\begin{array}{l}\text { BNP } \\
\text { [pg/ml] }\end{array}$ & preop & $\begin{array}{l}\text { ECC } \\
\text { start }\end{array}$ & $\begin{array}{c}\text { AXCL } \\
\text { open }\end{array}$ & $\begin{array}{l}\mathbf{1 0} \text { min Re- } \\
\text { perf. }\end{array}$ & $\begin{array}{l}\text { ECC } \\
\text { end }\end{array}$ & $\begin{array}{c}\mathbf{1 5} \\
\text { min }\end{array}$ & $\begin{array}{c}\mathbf{3 0} \\
\text { min }\end{array}$ & $\begin{array}{c}\mathbf{4 5} \\
\text { min }\end{array}$ & $\begin{array}{l}\mathbf{6 0} \\
\text { min }\end{array}$ \\
\hline BNP & 9.8 & 268.6 & 363.5 & 340.3 & 267.7 & 332.2 & 374.2 & 315.3 & 367.2 \\
& \pm 1.1 & \pm 62.1 & \pm 90.2 & \pm 84.5 & \pm 92.2 & \pm 69.5 & \pm 1.2 & \pm 4.0 & \pm 67.3 \\
& & $\mathbf{P}<\mathbf{0 . 3 6}$ & & & & & & & $\mathbf{P}<\mathbf{0 . 0 0 1}$ \\
\hline Control & 9.0 & 270.8 & 98.0 & 63.0 & 131.8 & 63.2 & 42.8 & 36.9 & 39.3 \\
& \pm 1.2 & \pm 89.9 & \pm 28.2 & \pm 9.3 & \pm 49.6 & \pm 11.3 & \pm 5.9 & \pm 4.8 & \pm 19.6 \\
& & $\mathbf{P}<\mathbf{0 . 0 0 4}$ & & & & & & & $\mathbf{N S}$ \\
\hline
\end{tabular}




\section{Figure legends}

Figure 1: Final data 60 minutes after the termination of extracorporeal circulation (ECC) showed that administration of BNP led to a significant increase in cardiac output in the BNP group compared to the control group.

Figure 2: Final data 60 minutes after the termination of extracorporeal circulation (ECC) showed the cardiac index in the BNP group was significantly higher than in the control group, and markedly higher than the initial values within the BNP group.

Figure 3: The number of animals in the control group who required catecholamines to treat post-ischemic heart failure after extracorporeal circulation $(\mathrm{ECC})$ was significantly higher than in the BNP group (AXCL = aortic cross clamping)

Figure 4: Mean systemic vascular resistance (SVR) was markedly lower (from 15 minutes after ending extracorporeal circulation (ECC) to the end of procedures) in the BNP group.

Figure 5: For the time period after reopening the aortic cross clamp to the end of the procedures, mean creatine phosphokinase (CPK) was significantly lower in the BNP group than in the control group 


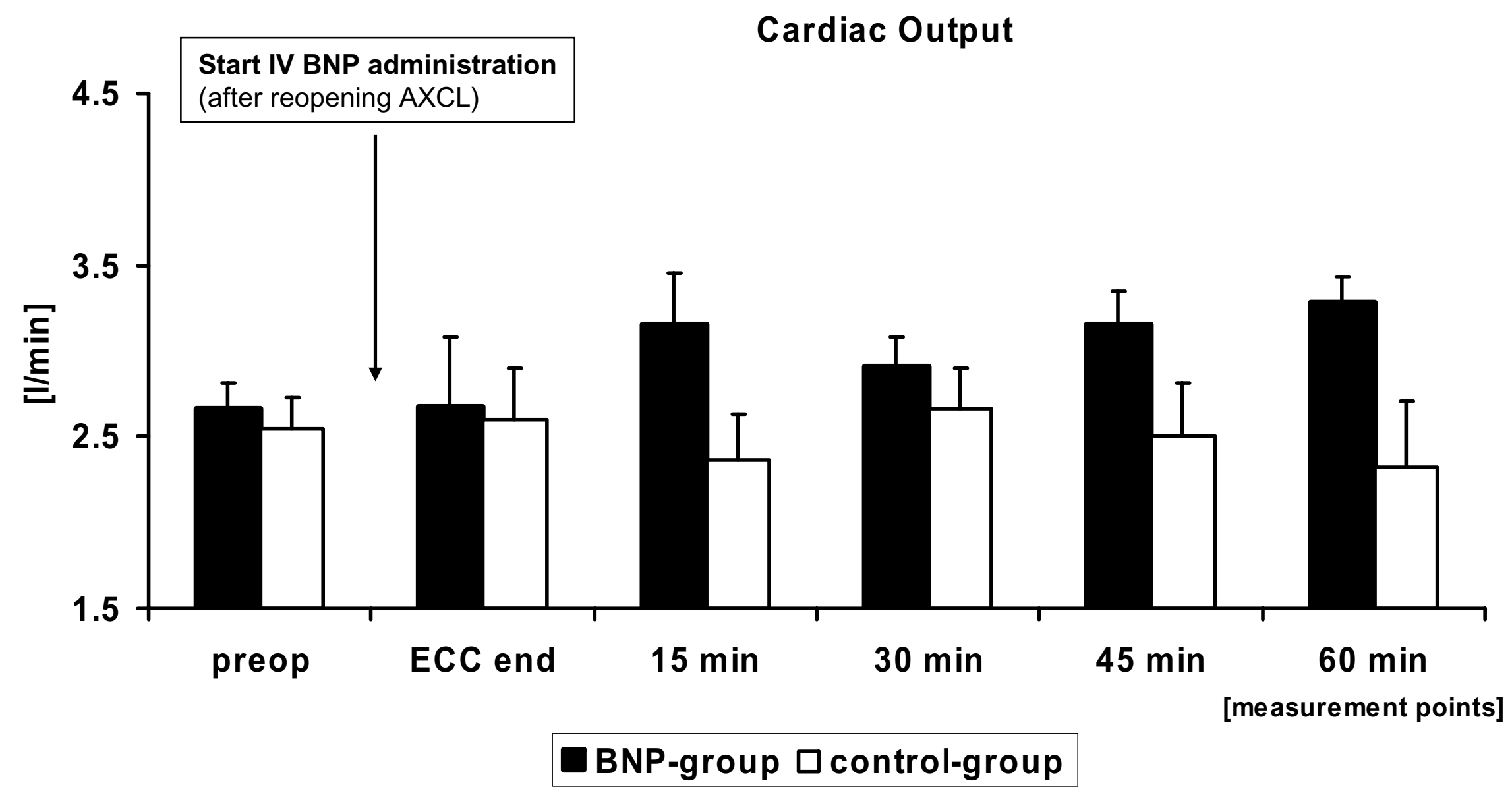




\section{Cardiac Index}

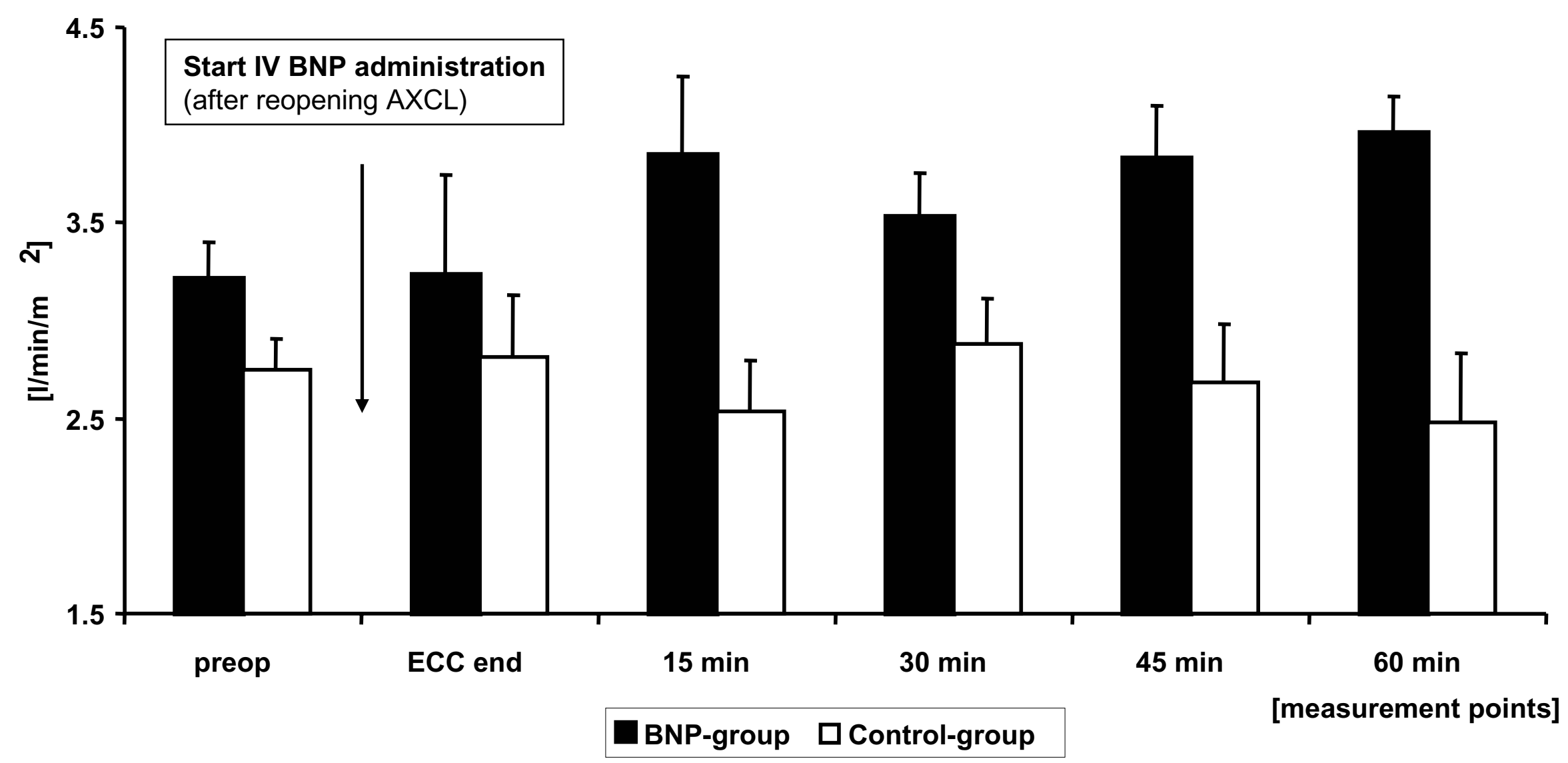


Catecholamines

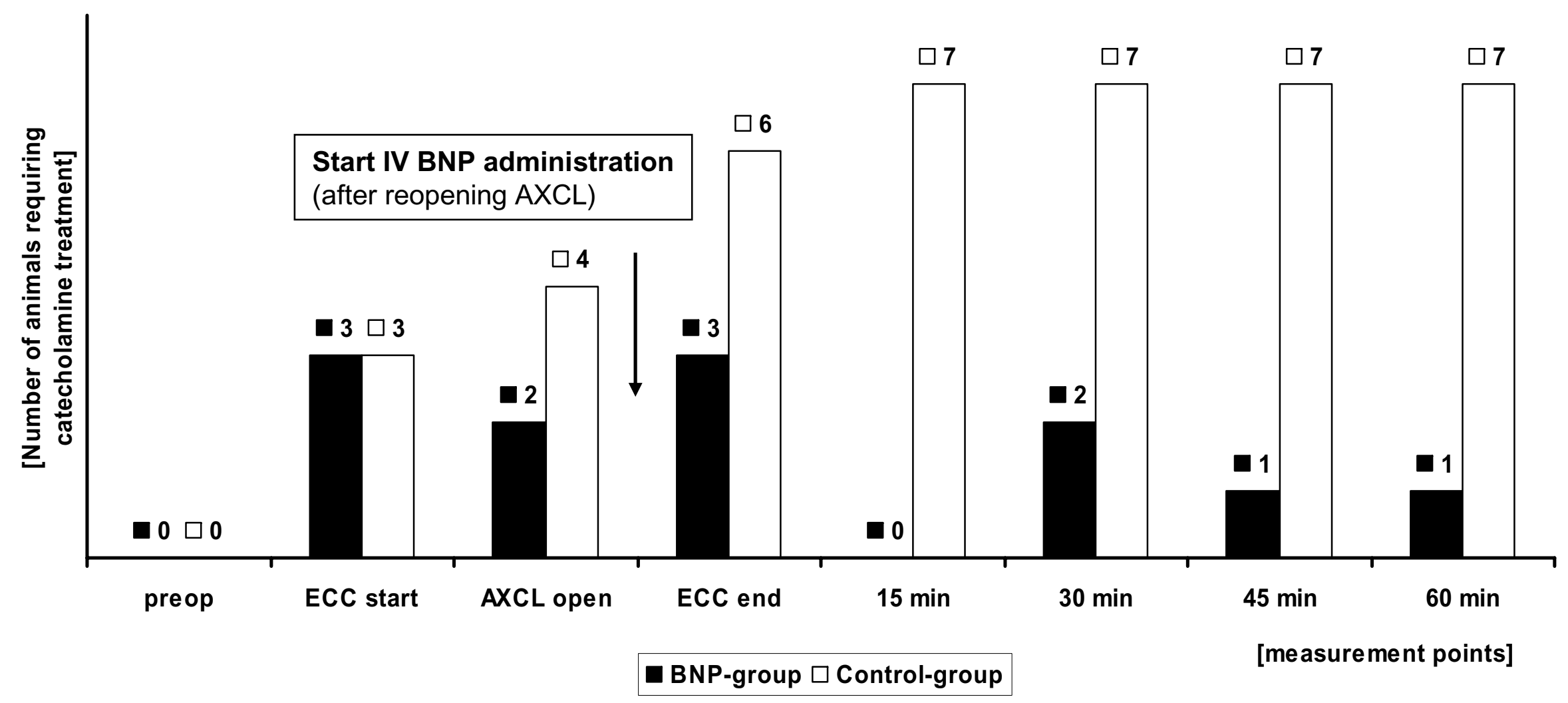




\section{Systemic vascular resistance}

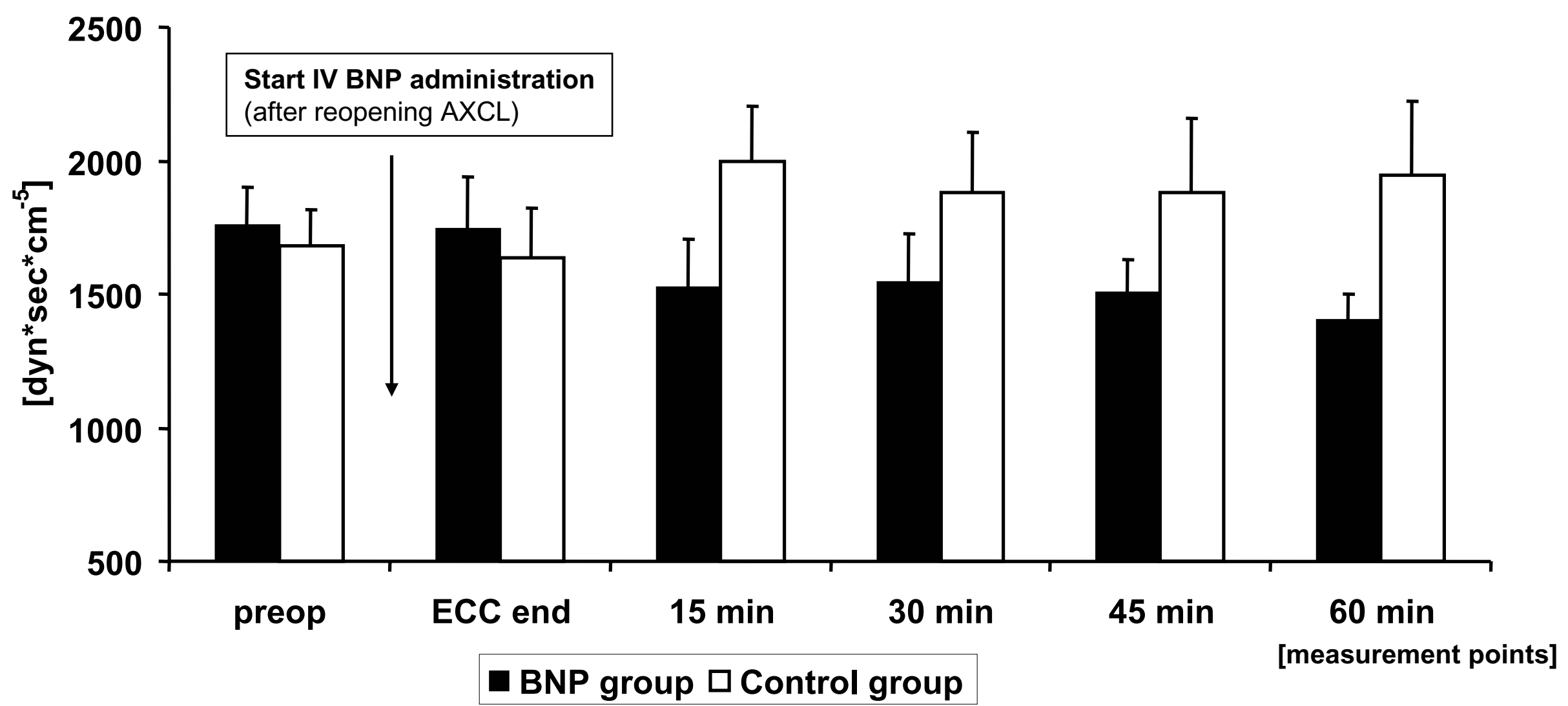




\section{Creatine phosphokinase}

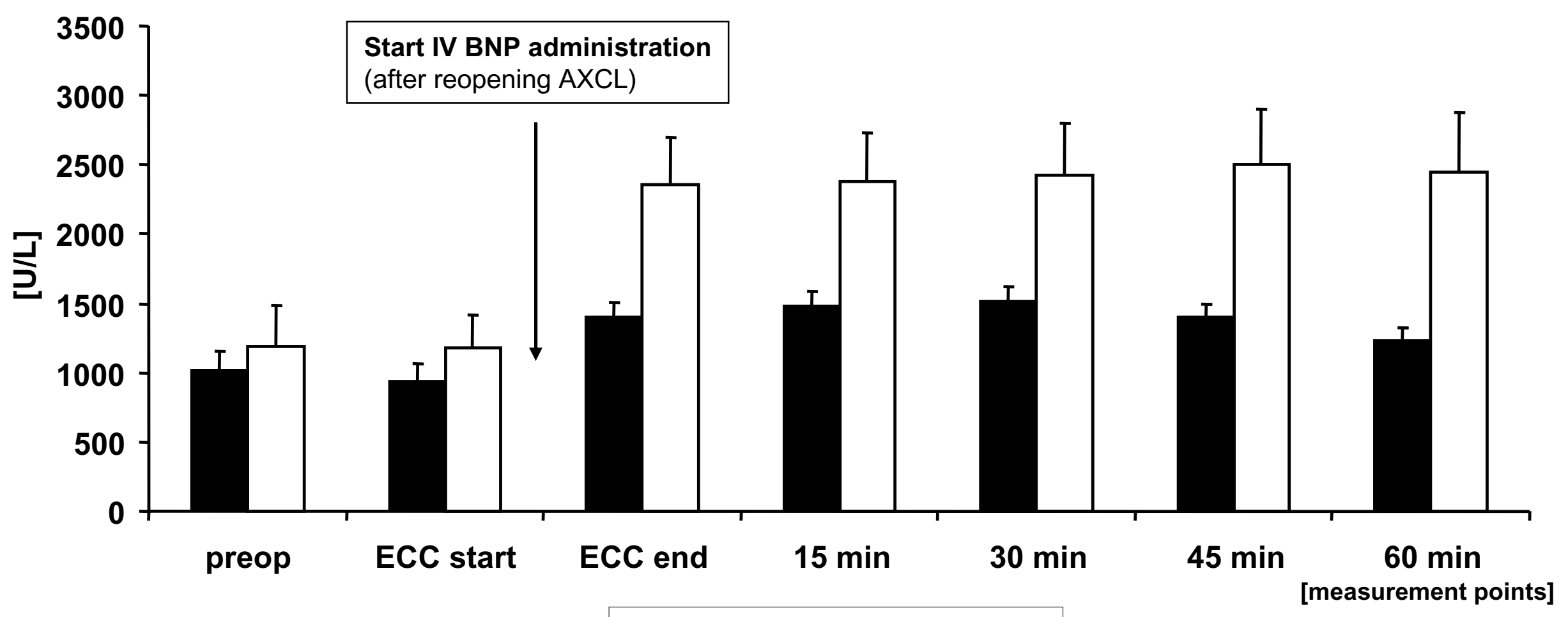

